\title{
Accurate Removal of Implanted Gallium and Amorphous Damage from TEM Specimens after Focused Ion Beam (FIB) Preparation
}

\author{
P. Nowakowski, C.S. Bonifacio, M.J. Campin, M.L. Ray, P.E. Fischione \\ E.A. Fischione Instruments, Inc., Export, PA 15632 USA
}

One of the most popular tools for TEM specimen preparation is gallium focused ion beam (FIB). It is well known that the FIB's high-energy Ga ions can damage a specimen's crystalline structure by introducing lattice defects (strain induction). FIB milling can also implant gallium ions into the specimen surface and cause surface amorphization [1]. An accurate and reproducible specimen preparation method that removes gallium and amorphous damage after FIB processing is necessary for TEM analysis. This work demonstrates how the quality of TEM specimens after FIB can be improved by using low energy argon ion milling.

FIB cross-section specimens were lifted out from monocrystal (100)[011] silicon using a $30 \mathrm{keV}$ $\mathrm{Ga}$ ion beam and thinned to $100 \mathrm{~nm}$ using various acceleration voltages. The specimens and $\mathrm{Ga}$ implantation thickness were quantified by X-ray characteristic emission measurement generated by the electron beam in the specimen. Thickness can be determined using the $\varphi(\rho z)$ model (the XPP approach proposed by Pouchou, et al. [2]) by comparing predicted and measured k-ratios. $\varphi(\rho z)$ is a function that describes the distribution of emerging X-ray intensity as a function of depth, where $z$ is the depth, $\rho$ is the mass per unit volume, and $\rho z$ is the mass thickness.

The implanted gallium thickness layer was measured following FIB thinning and again following low energy $500 \mathrm{eV}$ argon ion milling using the NanoMill ${ }^{\circledR}$ TEM specimen preparation system [Fischione Instruments]. X-ray characteristic emission measurement was performed using the $150 \mathrm{~mm}^{2} \mathrm{X}-\mathrm{Max}^{\mathrm{N}}$ detector [Oxford Instruments]. Specimens and Ga implanted layer thickness, before and after argon ion milling was evaluated using the AZtec software tool, LayerProbe [Oxford Instruments]. The results are shown in Table 1. The energy dispersive X-ray spectroscopy (EDS) data acquired before and after ion milling show complete removal of implanted gallium (Figure 1). The high quality of the specimen was then confirmed by highresolution transmission electron microscopy (HRTEM) (Figure 2). The uncertainty of the thickness measurements was estimated, as described by the method in Ancey, et al. [3] and Nowakowski, et al. [4].

Quantification of amorphous layer damage vs gallium implantation by FIB preparation and its removal using $\mathrm{NanoMill}^{\circledR}$ argon ion milling will be also discussed.

\section{References:}

[1] J Mayer et al, MRS Bull. 32 (2007), p. 400.

[2] JL Pouchou, F Pichoir and D Boivin in "Microbeam Analysis”, eds. JR Michaels and P

Ingram (San Francisco Press, San Francisco), p. 120.

[3] M Ancey, F Bastenaire, and R Tixier, J. Phys. D: Appl. Phys. 10 (1977), p. 817.

[4] P Nowakowski et al, Surf. Sci. 605 (2011), p. 848. 
Table 1. Silicon specimen thickness and Ga-implanted layer thickness for each specimen side before and after ion milling.

\begin{tabular}{lcc}
$\begin{array}{l}\text { Specimen preparation } \\
\text { method }\end{array}$ & $\begin{array}{l}\text { Silicon } \\
\text { thickness }\end{array}$ & $\begin{array}{l}\text { Gallium implanted } \\
\text { layer (each side) }\end{array}$ \\
\hline $30 \mathrm{keV} \mathrm{FIB}$ & $100 \mathrm{~nm}$ & $1.5 \pm 0.1 \mathrm{~nm}$ \\
\hline $5 \mathrm{keV} \mathrm{FIB}$ & $130 \mathrm{~nm}$ & $0.3 \pm 0.08 \mathrm{~nm}$ \\
\hline $30 \mathrm{keV} \mathrm{FIB}$ and $500 \mathrm{eV}+300 \mathrm{eV}$ Ar ion milling & $70 \mathrm{~nm}$ & $0 \mathrm{~nm}$ \\
\hline
\end{tabular}

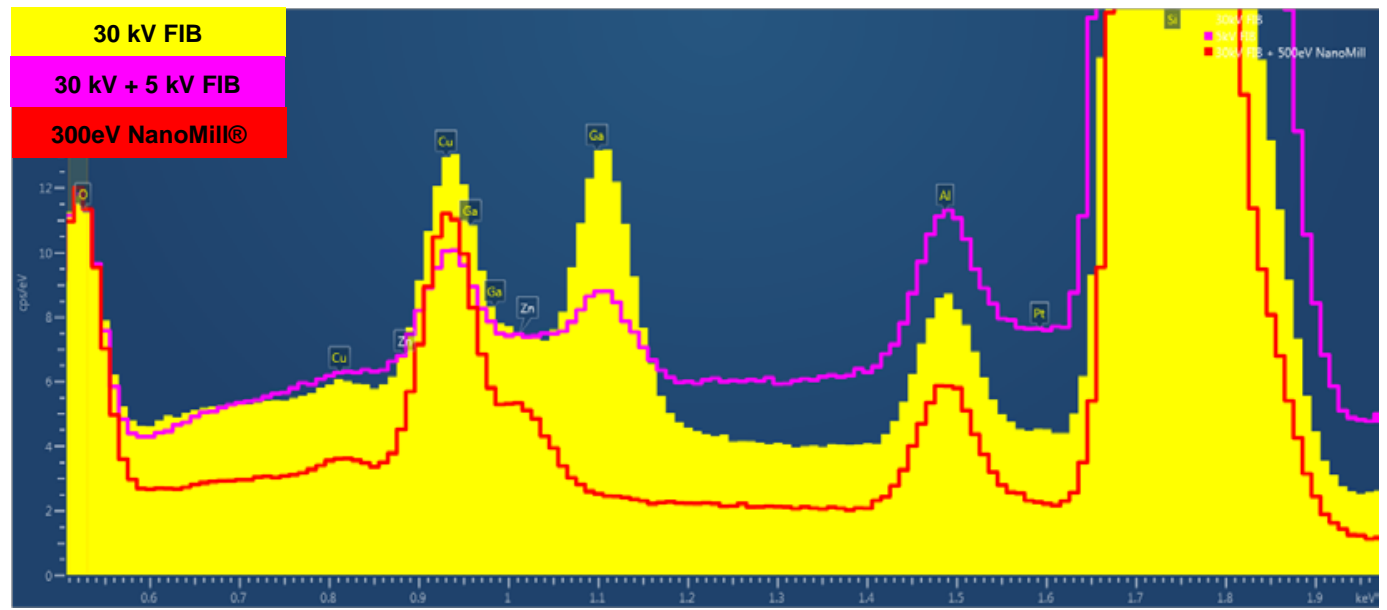

Figure 1. EDS spectra before and after ion milling. Specimen thinned at $30 \mathrm{keV}$ (yellow), $5 \mathrm{keV}$ (pink) Ga FIB, and $300 \mathrm{eV}$ ion milling (red).
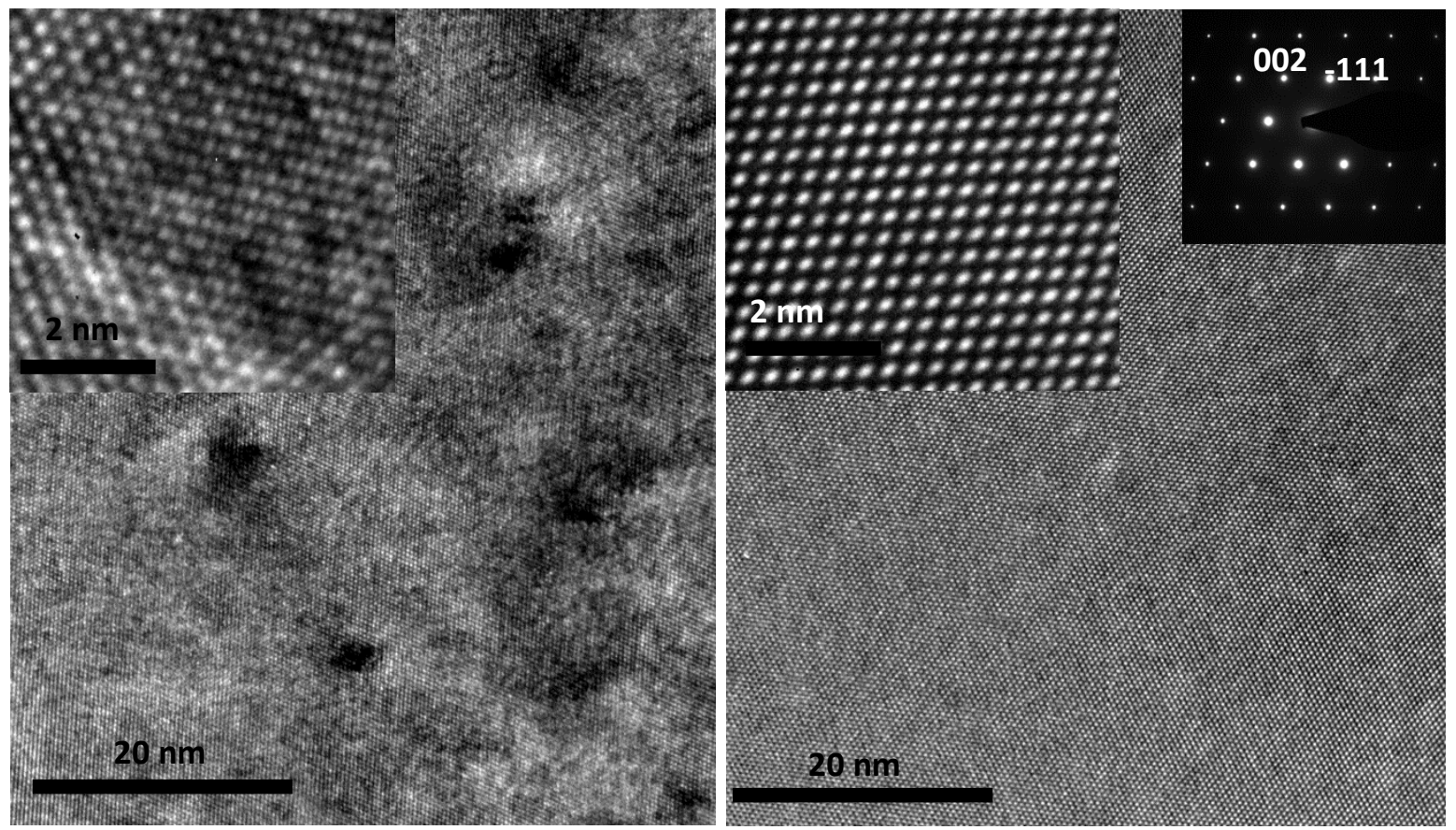

Figure 2. HRTEM images obtained at $200 \mathrm{kV}$ from monocrystal silicon at [011] zone axis after $30 \mathrm{keV}$ FIB gallium thinning (left), and after $300 \mathrm{eV}$ argon ion milling (right). 